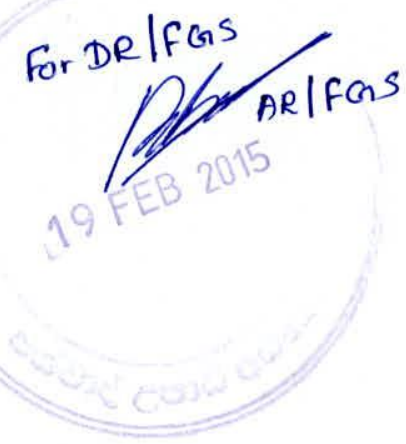

Antiglycation and antioxidant activities of some selected medicinal plants and selective value addition to Syzygium cumini (Madan) decoction by

Pathirage Rupika Damayanthi Perera 


\section{Antiglycation and antioxidant activities of some \\ selected medicinal plants and selective value addition to Syzygium cumini (Madan) decoction}

Pathirage Rupika Damayanthi Perera

Thesis submitted to the University of Sri Jayewardenepura for the award of the Degree of Doctor of Philosophy in Food Science on 2014 


\section{Certification of supervisors}

We certify that the candidate has incorporated all corrections additions and amendments recommended by the examiners.

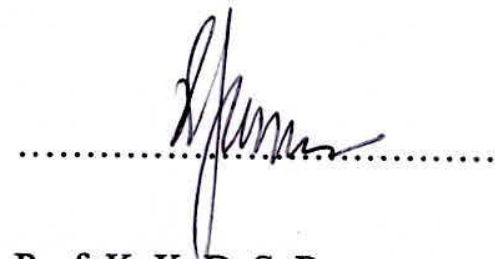

Prof. K. K. D. S. Ranaweera

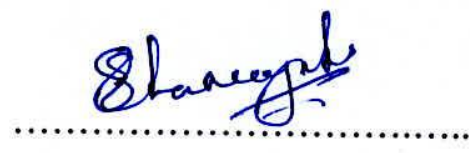

Prof. (Mrs) Sagarika Ekanayake 


\section{DECLARATION}

The work described in this thesis was carried out by me under the supervision of Professor K.K.D.S.Ranaweera, Director, Bandaranaike Memorial Ayurvedha Research Institute and Senior Lecturer, Department of Food Science and Technology, University of Sri Jayewardenepura and Professor Sagarika Ekanayake, Head, Department of Biochemistry, Faculty of Medical Sciences, University of Sri Jayewardenepura. The report on this has not been submitted in whole or in part to any University for another Degree/Diploma.

We certify that the above statement made by the candidate is true and that thesis is suitable for submission to the University for the purpose of evaluation.

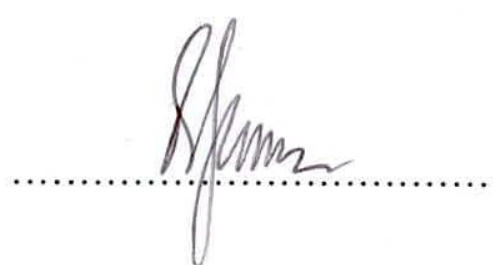

Prof. K. K. D. S. Ranaweera

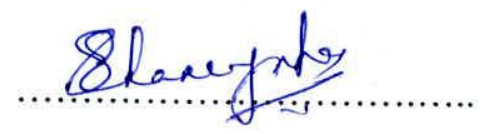

Prof. (Mrs) Sagarika Ekanayake 
Table of Contents

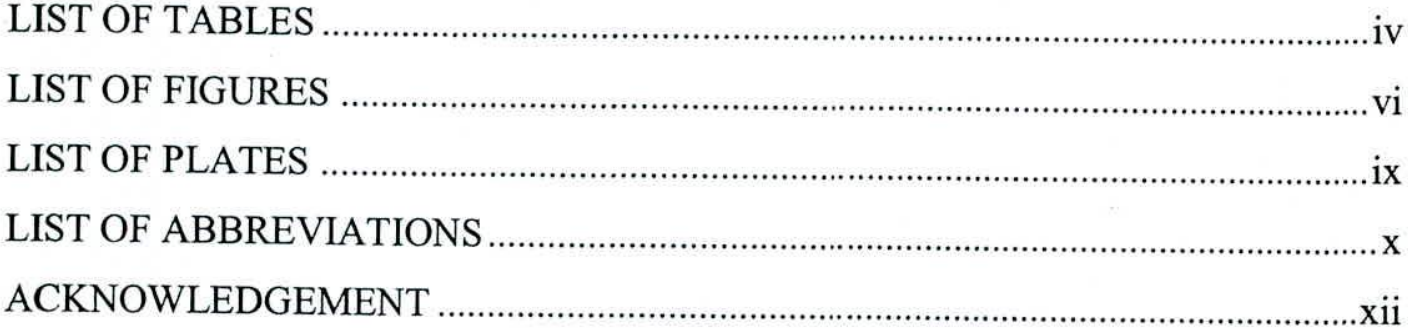

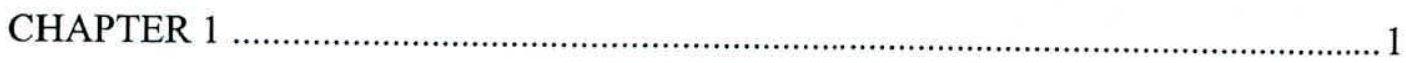

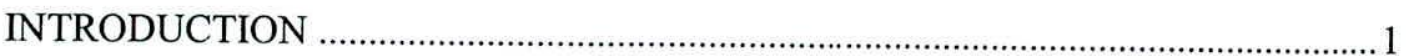

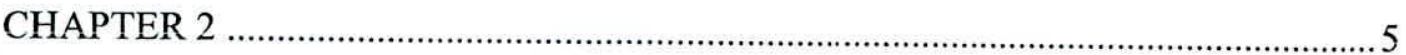

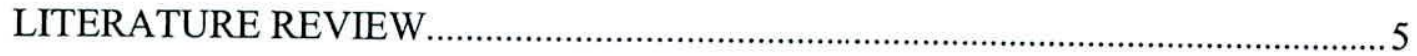

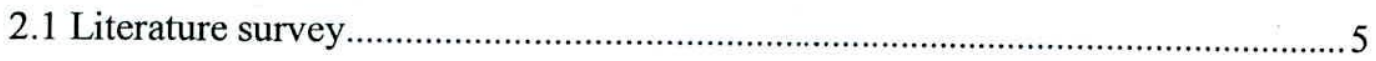

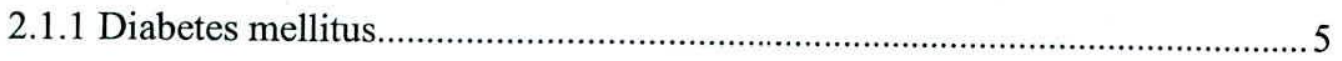

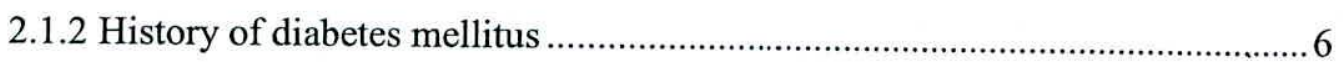

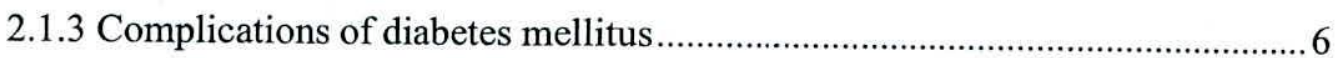

2.1.4 Formation of Advanced Glycation End Products in diabetes mellitus .............. 8

2.1.5 Chemistry of advanced Glycated End Products ............................................. 10

2.1.6 Formation of Free radicals in diabetes mellitus.............................................. 12

2.1.7 Chemistry of antioxidant compounds ........................................................... 13

2.1.8 Mechanisms of action of antiglycation compounds ........................................15

2.1.9 Mechanisms of action of antioxidant compounds ........................................... 15

2.2 Medicinal plants used in the treatment of diabetes mellitus ................................... 16

2.2.1 Selected medicinal plants used in the study...................................................220

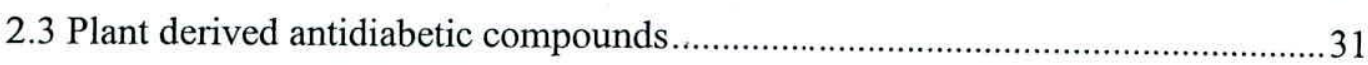

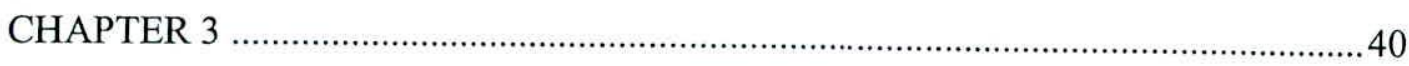

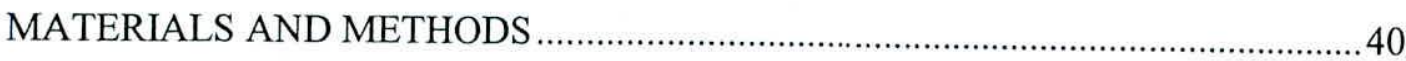

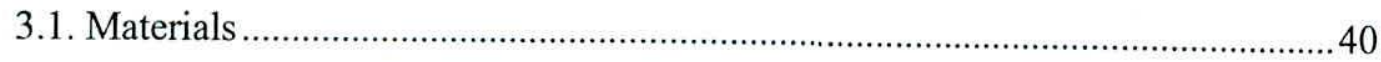

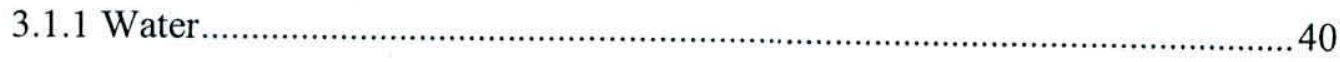

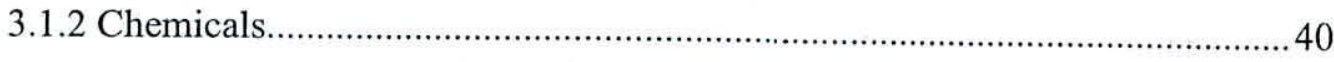

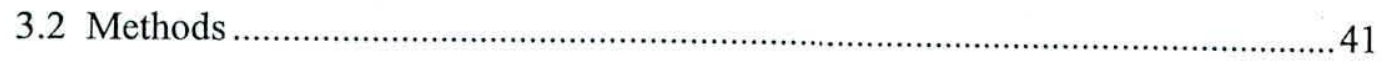


3.2.1 Selection of the plant materials for the study

3.2.2 Collection of plant materials.

3.2.3 Identification of plant materials.

3.3 Preparation of samples

3.3.1 Preparation of plant materials 44

3.3. 2 Preparation of herbal decoctions. 44

3.3.3 Antiglycation activity by Bovine Serum Albumin assay 44

3.3.4 Antioxidant potential by DPPH assay 45

3. 3.5 Antioxidant activity by ABTS assay 46

3.3.6 Total phenolic content 48

3.4 Preliminary phytochemical analysis of Syzygium cumini water extract and ethanolic extract

3.4.1 Preparation of extracts for phytochemical screening

3.6 Preparation of ready to serve drink

3.6.1 Formulations of ready to serve herbal drink prepared with $S$. cumini decoction

3.6.2 Physical chemical and microbiological analysis of the ready to serve herbal drink

3.7 Statistical analysis

3.8 Extraction, Isolation and characterization of bioactive compounds from plant extracts.

3.8.1 Activity guided fractionation

CHAPTER 4

4.1 Results of antioxidant activity.....

4.1.1. DPPH antioxidant activity

4.1.2. ABTS antioxidant activity

4.1.3 Calibration curve of Trolox for determination of ABTS antioxidant assay ...67

4.2 Antiglycation activity of the plants

4.3 Total phenolic content of the plants

4.3.1 Calibration curve of Gallic acid for the determination of total phenolic content. 
4.4 Phytochemical analysis of S.cumini extracts .71

4.4.1 Total solids and moisture content of the $S$. cumini bark decoction .72

4.5 Results of ready to serve herbal drink 72

4.4.1 Results of sensory analysis of herbal drink 72

4.5.2 Physical characteristics of the herbal drink 73

4.5.3 Antiglycation activity of herbal drink 74

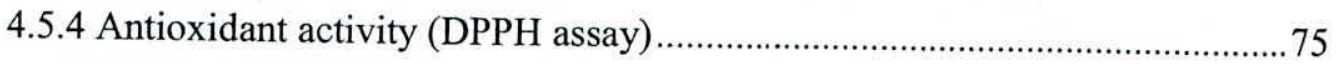

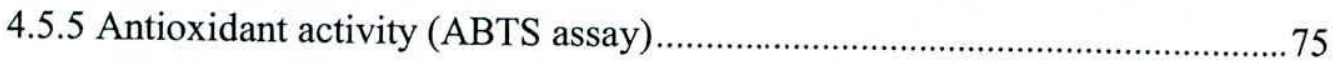

4.6 Results of activity guided fractionation of $S$. cumini decoction. 76

4.6.1 Antioxidant potentials and antiglycation activity of the fractions of $S$. cumini decoction

4.6.2 Results of the compound isolation and identification.

CHAPTER 5 .90

DISCUSSION 90

CHAPTER 6 108 CONCLUSION

REFERENCES

APPENDICES i

Appendix 1- List of Publications and Communications arising from the present work.i Appendix 11- Statistical calculations of antioxidant activity .iii 


\section{LIST OF TABLES}

Table 2.1

Medicinal plants commonly used in the treatment of

diabetes mellitus

Table $3.1 \quad$ Treatment combination of the herbal drink

Table 4.1.1

In vitro $\mathrm{DPPH}$ antioxidant activity of plant materials

Table 4.1.2

In vitro $\mathrm{ABTS}$ antioxidant activity of plant materials

Table 4.2.1

In vitro Antiglycation activity of plant materials

69

Table 4.3

Total phenolic content of plant materials

70

Table 4.4

Preliminary phytochemical Analysis of Syzygium

72

cumini water extract and ethanolic extract

Table 4.5.1.1

Average ranks of Sensory score for the developed

formulas of the herbal drink

Table 4.5.1.2 Statistical outcome for the response of the 74 respondents for sensory stimuli

Table 4.5.2 Physical characteristics of the herbal drink

Table 4.5.3 Antiglycation activity of herbal drink 
Table 4.5.5 Antioxidant activity of herbal drink (ABTS assay)

Table 4.5.6.1 The total viable count of the herbal drink

Table 4.6.1

DPPH and ABTS activities and antiglycation activity 78 of the fractions

Table 4.6.2 $\mathrm{R}_{\mathbf{f}}$ values of standards and phenolic compounds in $S$. 81 cumini ethyl acetate fraction

Table 4.6.3

$\mathrm{R}_{\mathbf{f}}$ values of phenolic compounds in $S$. cumini 85 decoction and RTS 


\section{LIST OF FIGURES}

Figure 2.1 Simplified reaction pathway involved in the formation of

Advanced Glycated End Products

Figure 2.2 Non Fluorescent/ Non cross linked Advanced Glycated

End Products.

Figure 2.3 Fluorescent/ Cross linked Advanced Glycated End Products

Figure 2.4 Phytochemical constituents isolated from S. cumini (L.)

Figure 2.4.1 Basic flavonoids skeleton

Figure 2.4.2 Structure of Arbutin

Figure 2.4.3 Structure of Luteolin

Figure 2.4.4 Structure of Flavanones

Figure 2.4.5 Structure of Flavonols

Figure 2.4.6 Structure of Cyanidine

Figure 2.4.7 Structure of Genistin

Figure 2.4.8 Structures of Phenolic acids

Figure 2.4.9 Structure of Mitragynine

Figure $3.1 \quad$ Locations of plants

Figure 3.2 Flow diagram of the preparation of ready to serve herbal drink $\mathbf{5 6}$ using S. cumini bark decoction

Figure 4.1 TLC of ethyl acetate fraction of S. cumini under UV-Vis light 79 $(254 \mathrm{~nm})$ 
Figure 4.2 TLC of ethyl acetate fraction of S. cumini under UV light $(366 \mathrm{~nm})$

Figure 4.3 TLC of ethyl acetate fraction of $S$. cumini cospotting technique

Figure 4.4 TLC of Ethyl acetate fraction of S. cumini cospotting technique

Figure 4.5 Ethyl acetate fraction of S. cumini decoction and RTS

Figure 4.6 HPLC chromatogram of ready to serve herbal drink made of S.cumini decoction

Figure 4.7 Expanded HPLC Chromatogram of ready to serve herbal drink

Figure 4.8 Spectrums before and after spiking the sample with Gallic acid

Figure 4.9 Spectrums before and after spiking the sample with Ellagic acid

Figure 4.9.1 LC-UV spectrum of Ellagic acid obtained from RTS

Figure 4.9.2 LC-UV spectrum of Gallic acid obtained from RTS

Figure 5.0 Summary of the results of DPPH antioxidant potentials of the decoctions

Figure 5.1 Summary of the results of ABTS antioxidant potentials of the decoctions.

Figure 5.2 Summary of the results of antiglycation potentials of the 95 decoctions

Figure 5.3 Summary of the results of total phenolic contents of the $\mathbf{9 8}$ decoctions

Figure 5.4 Antiglycation and DPPH potentials of ready to serve herbal $\mathbf{1 0 3}$ drink

Figure 5.5 ABTS potential of ready to serve herbal drink 
Figure 5.6.1 Structure of Gallic acid

Figure 5.6.2 Structure of Umbelliferon

Figure 5.6.3 Structure of Ellagic acid 


\section{LIST OF PLATES}

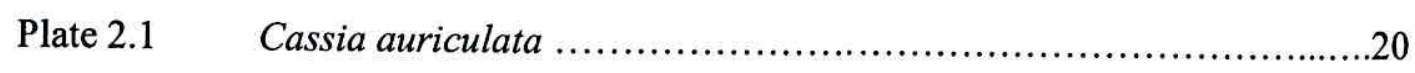

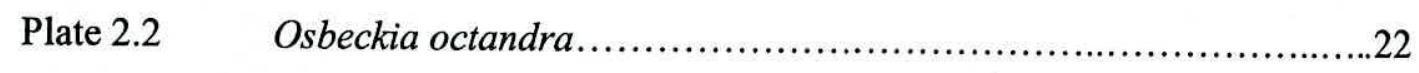

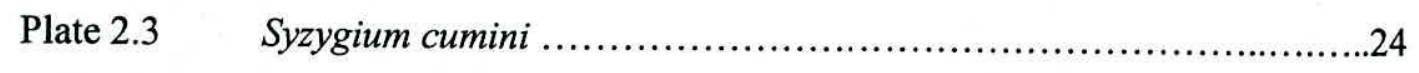

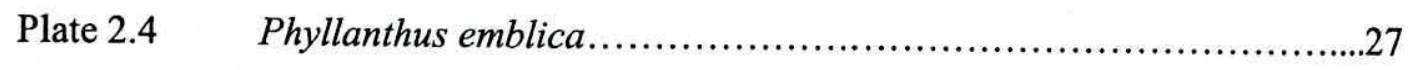

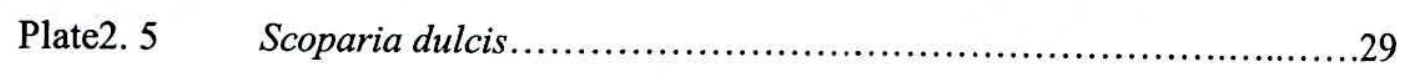




\section{LIST OF ABBREVIATIONS}

\begin{tabular}{|c|c|}
\hline ABTS & 2,2'-azino-bis (3-ethylbenzothiazoline-6-sulphonic acid) \\
\hline DPPH & 2,2-diphenyl-1-picrylhydrazyl \\
\hline TEAC & Trolox Equivalent Antioxidant Capacity \\
\hline GAE & Gallic Acid Equivalent \\
\hline TLC & 'Thin Layer Chromatography \\
\hline $\mathrm{R}_{\mathrm{f}}$ & Refractive Index \\
\hline IGT & Impaired Glucose Tolerance \\
\hline AGEs & Advanced Glycated End Products \\
\hline IFG & Impaired Fasting Glycemia \\
\hline DKA & Diabetic Keto Acidosis \\
\hline $\mathrm{HNC}$ & Hyperosmolar Non-ketonicoma \\
\hline LA & Lactic Acidosis \\
\hline CML & Carboxy methyl lysine \\
\hline CEL & Carboxy ethyl lysine \\
\hline MOLD & Methylglyoxal induced lysine dimer \\
\hline GOLD & Glyoxal derived lysine dimer \\
\hline $\mathrm{O}_{2 \cdot-}$ & Superoxide anion \\
\hline$\cdot \mathrm{OH}$ & Hydroxyl radical \\
\hline ROS & Reactive oxygen species \\
\hline RNS & Reactive nitrogen species \\
\hline STZ & Streptozotocin \\
\hline PBS & Phosphate buffered saline \\
\hline FC & Folin Ciocaltue \\
\hline BHT & Butylated Hydroxy Toluene \\
\hline
\end{tabular}


ANOVA Analysis of variance

HAT Hydrogen Atom Transfer

SET Single Electron Transfer

TSS Total Soluble Solid

HPLC High Performance Liquid Chromatography

LC UV- Vis Liquid Chromatographic Ultra Violet - Visible 


\section{ACKNOWLEDGEMENT}

I owe my deepest gratitude to my supervisors Prof. K.K.D.S Ranaweera, Professor of Food Science and Technology, University of Sri Jayewardenepura and The Director, Bandaranayake Memorial Ayurvedha Research Institute, Nawinna and Prof. Sagarika Ekanayake, Professor of Biochemistry, University of Sri Jayewardenepura for their valuable guidance, advice and the encouragement given throughout the study sparing their valuable time in bringing the study to successful completion.

My special thanks to Prof. Arthur Bamunuaarachchi, Professor of Applied Chemistry, University of Sri Jayewardenepura, for the encouragement and advice given throughout the study. I wish to express my sincere thanks to Dr. Indira Wickramasinghe, Head, Department of Food Science and Technology and all academic and non academic staff of the Department of Food Science and Technology for providing facilities and helping in many ways to carry out the research work freely and successfully. Furthermore I would like to offer my gratitude to Dr. Jagath Wansapala and Dr. S.B Navarathna, Senior lecturers of the Department of Food Science and Technology for their constructive suggestions and the help given in data analysis. My appreciation goes to Mrs.Suraji Senanayake and Ms. Asha Balasooriya for encouraging me to complete the work successfully. I would be grateful to Mr.Chanaka Karunarathna and Mr.D.P Ruasinghe for the endless support given during the study period.

I oblige my gratitude to Prof. A.M Abeysekara, Professor of Chemistry, University of Sri Jayewardenepura, for the valuable sugessions and emcouragement given carryout the research successfully.

My apreciation to Dr. Srimal Premakumara, Director, Industrial Technology Institute and Mr. P. Ranasinghe, Senior research scientist at ITI, for providing laboratory facilities and guidance, sharing their knowledge and time without any hesitation to improve the quality of my resesrch work. I thank for the support given by Dr. Sunethra Kariyawasam, Dr. Sewwandi and staff of BMARI, Nawinna to carry out the literature survey of the research successfully.

Finally I praise to my beloved husband, son, daughter, other family members and friends for the encouragement to wind up with a successful outcome. 


\title{
Antiglycation and antioxidant activities of some selected medicinal plants and selective value addition to Syzygium cumini (Madan) decoction
}

\author{
by Pathirage Rupika Damayanthi Perera
}

\begin{abstract}
According to the current statistics of Diabetes Atlas of International Diabetes Federation, 285 million among the world population suffer from Diabetes mellitus. Oxidative stress due to the rapid formation of free radicals and protein glycation are the key molecular basis of macro and micro complications of diabetes mellitus. There is a growing tendency to use herbal treatments in Diabetes mellitus due to the minimal adverse effects, safety and low cost. More than 500 traditional antidiabetic plants have been recorded in traditional medicine, but very few scientific investigations have been carried out to prove the efficacy of using these herbal plants in the treatment of Diabetes mellitus. Five medicinal plants commonly used in the treatment of diabetes mellitus were selected for the study by gathering information from the traditional and Ayurvedha medical practitioners. The selected herbal plant parts are Cassia auriculata flowers, Osbakia octandra leaves, Syzygium cumini bark, Phyllanthus emblica fruits and Scoparia dulcis whole plant. These are administrated as decoctions of poly herbal formulations and as individual plants, prepared according to the Ayurvedha pharmacopeia.
\end{abstract}

Decoctions of the five plants, prepared using the commercial samples available in the traditional herbal market and three fresh samples of each, collected from three different 
regions of Sri Lanka and dried under laboratory conditions were analyzed for the antiglycation potentials using the Bovian serum albumin assay, antioxidant potentials by ABTS and DPPH methods and total phenolic contents using Folin Ciocaltue method.

Decoctions of S. cumini bark, O. octandra and P. emblica showed significantly high antiglycation potentials in the range of $16.8-35.18,23.0-28.5,37.4-82.28 \mu \mathrm{g} / \mathrm{ml}$ while C. auriculata and $S$. dulcis showed moderate antiglycation potentials as 109-250 $\mu \mathrm{g} / \mathrm{ml}$ and $131-213 \mu \mathrm{g} / \mathrm{ml}$. The DPPH potentials were also significantly high in $S$. cumini, O. octandra and P. emblica and were in the range of 30.3-69, 55.5-98.4, 27.1$49.5 \mu \mathrm{g} / \mathrm{ml}$ respectively. C. auriculata and $S$. dulcis showed moderate DPPH potentials as $237-309$ and $437-540 \mu \mathrm{g} / \mathrm{ml}$. The highest ABTS potential was reported in $P$. emblica decoction of commercial sample as 2764 TEAC mmol/g, other laboratory dried samples showed 1393-1871 TEAC mmol/g and S. cumini, O. octandra also contained significantly high ABTS potentials in the ranges of 1544-1897, 794-1375 TEAC $\mathrm{mmol} / \mathrm{g}$ respectively. Moderate ABTS potentials were showed by $C$. auriculata and $S$. dulcis $(313-648,549-615$ TEAC $\mathrm{mmol} / \mathrm{g})$. The total phenolic contents were significantly high in S.cumini, O.octandra and P.emblica as 819-867,483-666, 491$625 \mathrm{mg} \mathrm{GAE} / \mathrm{g}$ and moderate values were given by $C$.auriculata and S. dulcis as 215459, 131-186 mg GAE/g.

S. cumini commercial sample with the highest antiglycation potential, significantly high DPPH and ABTS potentials and phenolic contents was further analyzed for the availability of phytochemical constituents and the decoction contained glycosides, tannins, flavonoids, saponins and phenols.

A ready to serve herbal drink was developed using the decoction of S. cumini commercial sample, by selecting the best consumer acceptable formula among four 
formulations developed based on the two factor factorial designing and analyzing data obtained using 30 numbers of untrained sensory panelists. The herbal drink contained $20 \mathrm{ml}$ of the $S$. cumini decoction and the dosage was below the recommended level in Ayurvedha Pharmacopeia. Sucralose $(0.01 \%)$ was used to mask the bitter and astringent taste of the drink and was one tenth of the recommend level. Storage studies of the herbal drink were conducted for three months under refrigerated conditions. Its physical characteristics (colour, $\mathrm{pH}$ value and total soluble solids $\left(\mathrm{Brix}^{\circ}\right)$ ) and antiglycation and antioxidant potentials were measured at 45 days intervals. Microbiological assays for viable colony counts for bacteria and fungi were conducted at 15 days intervals. No significant difference was found in physical characteristics and the drink was microbiologically safe during the storage period. Antiglycation potentials were in the range of $35.8-41.1 \mu \mathrm{g} / \mathrm{ml}$ and ABTS and DPPH potentials were in the range of $82.3-87.0 \mu \mathrm{g} / \mathrm{ml}, 1314-1095 \mathrm{TEAC} \mathrm{mmol} / \mathrm{g}$ and no significant decrease in the potentials during the storage period were detected.

Activity guided fractionation of the decoction of the $S$. cumini commercial sample was carried out by sequential extraction of organic solvents and hexane, ethyl acetate and water fraction and were tested for antiglycation, ABTS and DPPH antioxidant potentials. No DPPH activity was found in hexane fraction but ABTS and antiglycation potentials were $320 \mathrm{TEAC} \mathrm{mmol} / \mathrm{g}, 119 \mu \mathrm{g} / \mathrm{ml}$ respectively. Ethyl acetate fraction showed the highest DPPH potential as $1.39 \mu \mathrm{g} / \mathrm{ml}$ and ABTS and antiglycation potentials were as $3151 \mathrm{TEAC} \mathrm{mmol} / \mathrm{g}$ and $5.2 \mu \mathrm{g} / \mathrm{ml}$ respectively. The highest ABTS potential was reported in the water fraction (5739 TEAC mmol/g) while DPPH and antiglycation potentials were 6.76 and $3.6 \mu \mathrm{g} / \mathrm{ml}$. 
Compound isolation of the ethyl acetate and water fraction was carried out by Thin Layer Chromatographic method (TLC), High Performance Liquid Chromatographic method and UV- Visible spectrophotometric method.

The presence of gallic acid, ellagic acid and umbelliferone were confirmed by the TLC method with similar $R_{f}$ values with standards and gallic acid and ellagic acid were further confirmed applying the co spotting technique.

The findings of the present investigation support in proving the antidiabetic properties of the above herbal plants on the basis of their efficacy in preventing the protein glycation and oxidative stress. This data prove the efficacy of using these plants in the treatment of diabetes mellitus for many years and might be useful in the herbal drug development industry. 